\title{
Protein Structure Predictions of historical silk textiles by ATR-FTIR spectroscopy
}

\author{
Sevim Akyuz, Tanil Akyuz, Banu Cakan and Sait Basaran
}

\begin{abstract}
In this study some historical silk textiles were investigated using Fourier transform infrared (FTIR) spectroscopy. The main aim of our research was to investigate conformational changes of silk protein, fibroin, caused by ageing depending on environmental conditions. Silk textiles obtained from the wall decorations of an Ottoman Kiosk (Istanbul-Turkey) and some excavated silk textile specimens obtained from Ancient Ainos excavations were investigated in comparison with those of new and 100 years old Bombyx mori silk specimens. It was found that structural transformations from $\beta$-sheet domain to $\beta$-turn and random coil conformations occur due to degradation. It was shown that IR spectroscopy provides a quantification of degradation of silk objects.
\end{abstract}

Keywords - ATR-FTIR spectroscopy, Fibroin, historical textile

\section{Introduction}

Silk is one of the most significant inventions in the history of human civilization. Silk fibres are used in different cultural heritage objects, mainly canvases and dresses. As a result of inadequate storage conditions materials degrade. Organic materials are especially sensitive to degradation and biodegradation. During the aging process silk proteins undergo changes in chemical and conformational structures.

Ancient Ainos (Enez, Turkey) was founded on the northern coast of the Aegean Sea. It is one of the most important archaeological sites in Turkey. The excavations in this area have been begun in 1971 and onwards till now. During the excavations in 2005-2006 years held at the site of Chapel Gregorios Neokaiserias some textile specimens were found. In our previous study [1] the textile fibres were identified as Bombyx mori silk. Textile specimens were composed of metal and silk parts. Flat metal filaments form palmate-like shapes were seen on the surface of the woven fabric.

Raw silk is a proteinaceous fibre consists of two major proteins: The main fibrous component fibroin, and amorphous protein sericin (2). Fibroin is a highly crystalline scleroprotein, which is very resistant to chemical agents and highly insoluble. Sericin is an albuminoid substance.

Sevim Akyuz and Tanil Akyuz

Physics Department, Istanbul Kultur University

Turkey

Banu Cakan and Sait Basaran

Department of Restoration and Conservation of Artefacts, Istanbul University, Turkey
In commercial use, sericin is normally removed by degumming. It is removed by treatment with warm water and soaps (degumming process); this treatment increases silk's resistance to microbial attack. However, some historic silks were composed of raw or partially degummed silk. Fibroin is largely formed from a hexapeptide repeat motif (Gly-Ala-Gly-Ala-Gly-Ser-), while sericin is dominated by the presence of hydroxyl (Ser, Thr, and Tyr), acidic (Asp and Glu), and basic (Lys, His, and Arg) amino acid residues $(2,3)$. Thus the fibroin and sericin spectra have very distinctive infrared signatures, and the presence of sericin can be inferred from the IR spectra of the silk textiles. The secondary structure of silk concerns primary its crystallinity. The crystal region of silk fibroin was mainly composed of $\beta$ sheet structure. In the literature, the ratio of two Amide I band intensities $\beta$-sheet relative to $\alpha$-helix or/and random coil arrangement has been considered a crystallinity index for historic silk fibroin as it reflects the relative proportion of the secondary structure of the polymer. Analogically, from the Amid III bands intensity rations conformation of the silk protein can be estimated. Koperska et al. $(4,5)$ have shown that the amino acid chain is affected also by both hydrolysis and oxidation. They proposed an estimator with view to monitoring the hydrolysis effect. It was proved that a band centred at $1318 \mathrm{~cm}^{-1}$ attributed to the vibration of $\mathrm{C}$ $\mathrm{H}$ bond shielded by $-\mathrm{COOH}$ groups from bicarboxylic acids formed upon peptide bond breaking $(4,5)$. Here we investigated degradation of several historical silk samples by using IR degradation estimators proposed by Koperska et al. $(4,5)$. In this study silk textiles obtained from the wall decorations of an Ottoman Kiosk (Istanbul-Turkey) and some excavated silk textile specimens obtained from Ancient Ainos excavations are investigated by Attenuated Total Reflectance-Fourier Transform Infrared spectroscopy (ATR-FTIR) in comparison with those of fresh and 100 years old Bombyx mori silk specimens and their degradation process will be discussed.

\section{Experimental}

In this study two silk canvases obtained from the wall decorations of an Ottoman Kiosk (Istanbul-Turkey) and some excavated silk textile specimens obtained from Ancient Ainos excavations are investigated in comparison with those of new and 100 years old Bombyx mori silk specimens. During the restoration process of the Imperial Pavilion (Hunkar kasri) of New Mosque, in August 2006, some parts of the silk canvases were found to be repaired previously. In this study the original canvas (estimated belong to $17^{\text {th }}$ century) and the other replica one was 
investigated. The photographs of the investigated samples were given in Fig 1.

The ATR-FTIR spectra of the samples were recorded on a Bruker Tensor FTIR spectrometer with diamond ATR unit. 200 sample and 20 background spectra were accumulated (2 $\mathrm{cm}^{-1}$ resolution). Standard correction for ATR spectrum was applied. Spectral manipulations such as baseline adjustment, smoothing, obtaining the second derivative and band fitting procedures, were performed using GRAMS/AI 7.02 (Thermo Electron Corporation) software package. Band fitting was done using Gaussian+Lorentzian function and fitting was undertaken until reproducible and converged results were obtained with squared correlations better than $\mathrm{r}^{2}$ $\sim 0.9999$. The second derivative profile gives valuable information about the position of the bands and band widths. Thus for the band fitting procedure (to locate the position of the peaks), the second derivative of the absorption spectrum was used as a guide. The second derivatives of the spectra were obtained by using Savitzky-Golay function (two polynomial degrees, 17 points).

\section{Results and discussion}

An arithmetical mean of the ATR-IR spectra collected for 4 different points of the historic samples was calculated and then the data was used for investigation of the degradation of the samples.

The mean IR spectra of some investigated samples were given in Fig 2. In the IR spectra of the all investigated samples, amide I (1700-1600 $\left.\mathrm{cm}^{-1}\right)$, amide II (1550-1500 $\left.\mathrm{cm}^{-1}\right)$ and amide III $\left(1300-1230 \mathrm{~cm}^{-1}\right)$ bands, which are characteristics of the protein structure, are observed. One can find from the figure some noticeable changes in both shape and intensity of the amide bands.

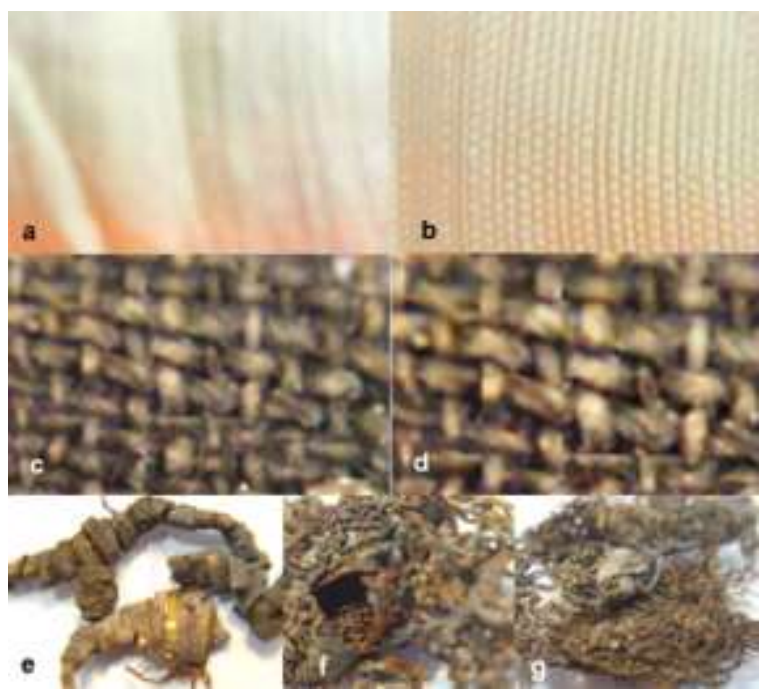

Figure 1. Photographs of the investigated silk samples; Fresh (a) and 100 years old Bombyx mori silk textiles (b), original (c) and replica (d) silk canvases obtained from

Imparial Pavillion of New mosque, excavated silk

specimens from Ancient Ainos excavations (e-g).

As seen in Fig 2 the decrease in Amid I, II and III intensities, indicating the loss of peptide structure with the samples age. The band component analysis of the amide I-II region of the original canvas (Fig 1c) and old silk textile (Fig 1b) are given in Fig.3. Amide I band intensities were used for investigation of the $\beta$-sheet relative to and random coil arrangement and amide III band intensities were compared for investigation of the crystallinity index.

We did not observe band component for antiparallel $\beta$ sheet structure around $1690 \mathrm{~cm}^{-1}$ in the IR spectrum of fresh $\mathrm{BM}$ silk, but a very weak band observed at $1698 \mathrm{~cm}^{-1}$ that can be attributable to antiparallel $\beta$-sheet structure in the IR spectra of 100 years old B.M silk (see Fig 3 b).

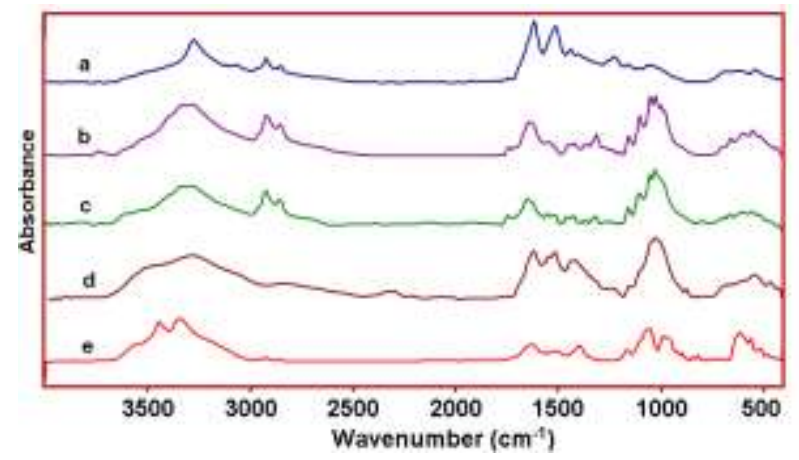

Figure 2. ATR-FTIR spectra of 100 years old Bombyx mori silk textile (a), different parts of the original canvases (b-c), excavated textiles $(\mathrm{d}, \mathrm{e})$.
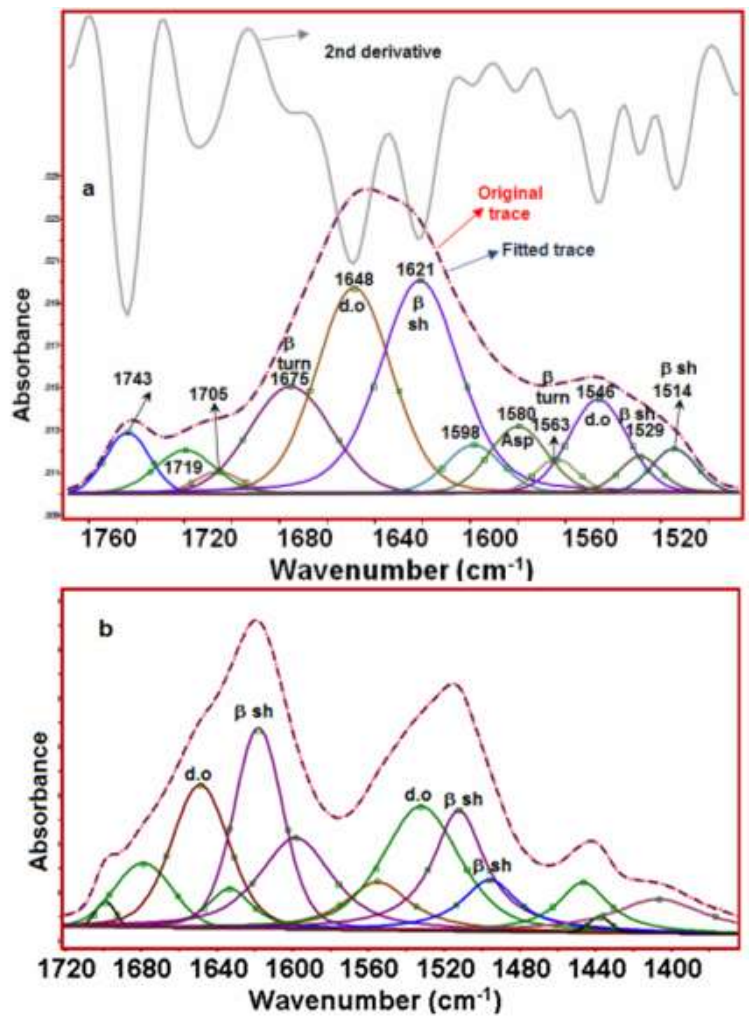

Figure 3. Band component analysis of the amide I and II regions of original canvas (a) and Bombyx mori silk textile (b). $\beta$-sh $=\beta$-sheet;d.o $=$ dis ordered structures. 


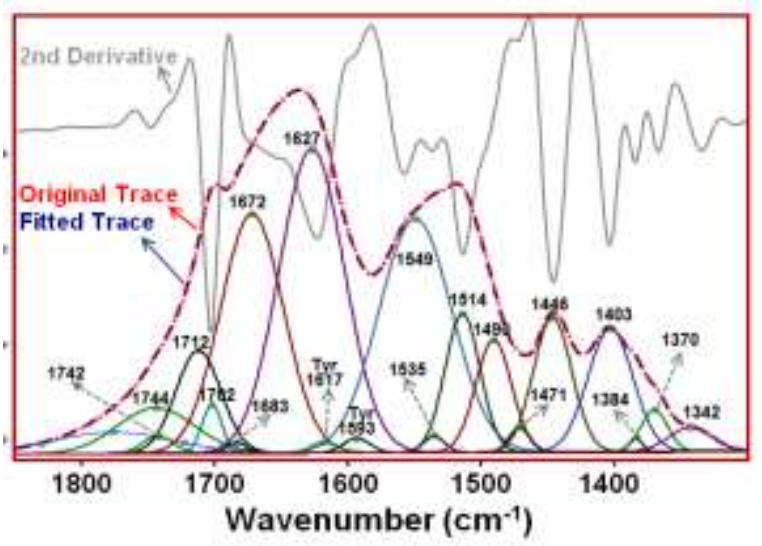

Figure 4. Band component analysis of the IR spectra of an ancient silk textile.

In the IR spectra of canvases and ancient silk textiles the growth of the band centered at $1699 \mathrm{~cm}^{-1}$ is observed (see Figs 3-4), additionally we also observed $\mathrm{C}=\mathrm{O}$ vibrations around 1743-1712 $\mathrm{cm}^{-1}$ indicating conformation alteration and breaking the peptide bands. These observations were also supported by arises of $1318 \mathrm{~cm}^{-1}$ band which is not present in the IR spectrum of fresh silk. This band was attributed to the vibration of $\mathrm{C}-\mathrm{H}$ bond shielded by $-\mathrm{COOH}$ groups from bicarboxylic acids formed upon peptide bond breaking.

\section{Conclusion}

The degradation of some historical silk samples were investigated by using crystallinity, oxidation and hydrolysis estimators proposed by Koperska et al. $(4,5)$. It was shown that quantization of degradation of historic silk textiles based on non-destructive ATR-FTIR analyses can performed and the condition of the historical silk textiles can be described. Conformational alteration in the protein structure depending on the age of the sample is clearly shown. The similar protein band structure of the ancient silk textiles indicated they have the same origin and age. The IR spectral investigation has shown that original canvas was more degraded than the replica canvases.

\section{References}

[1] S. Akyuz, T. Akyuz, B. Cakan and S. Basaran, "Investigations of the Historic Textiles Excavated from Ancient Ainos (Enez-Turkey) by Multiple Analytical Techniques," J. Mol. Struct., Vol 1073, pp 37-43, 2014.

[2] M-Y. Li, Y. Zhao, T. Tong, X-H. Hou, B-S. Fang, S-Q. Wu, X-Y. Shen, H. Tong, "Study of the degradation mechanism of Chinese historic silk (Bombyx mori) for the purpose of conservation" Polym. Degrad. Stab., Vol. 98, pp. 727-735, 2013

[3] P. Garside, P. Wyeth, "Crystallinity and degradation of silk: correlations between analytical signatures and physical condition on ageing" Appl Phys A-Mater, Vol. 89, pp. 871-876, 2007.

[4] M.A. Koperska , T. Lojewski, J. Lojewska, "Evaluating degradation of silk's fibroin by attenuated total reflectance infrared spectroscopy: Case study of ancient banners from Polish collections", Spectrochim. Acta A, Vol 135, pp 576-582, 2015.
[5] M.A. Koperska, D. Pawcenis, J. Bagniuk, M.M. Zaitz, M. Missori, T. Lojewski, J. Lojewska, "Degradation markers of fibroin in silk through infrared spectroscopy", Polymer Degradation and Stability, Vol 105, pp 185-1962014

About corresponding author:

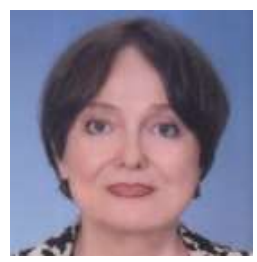

We have examined specimens of historical silk textiles using FTIR spectroscopy. The main aim of our research was to investigate conformational alterations of silk proteins caused by ageing and biodeterioration, and show the possibility of the quantization of degradation of historic silk by FTIR spectroscopy. 